\title{
Upregulation of miR-205 induces CHN1 expression, which is associated with the aggressive behaviour of cervical cancer cells and correlated with lymph node metastasis
}

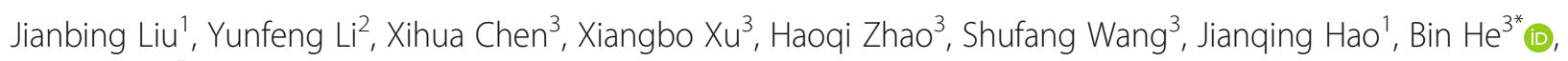
Shuyan Liu $^{4^{*}}$ and Jiedong Wang $^{3}$

\begin{abstract}
Background: Cervical cancer is the leading cause of cancer-related death in women worldwide. However, the mechanisms mediating the development and progression of cervical cancer are unclear. In this study, we aimed to elucidate the roles of microRNAs and a1-chimaerin (CHN1) protein in cervical cancer progression.

Methods: The expression of miR-205 and CHN1 protein was investigated by in situ hybridisation and immunohistochemistry. We predicted the target genes of miR-205 using software prediction and dual luciferase assays. The expression of mRNAs and proteins was tested by qRT-PCR and western blotting respectively. The ability of cell growth, migration and invasion was evaluated by CCK-8 and transwell. Cell apoptosis was analysed by flow cytometry analysis.
\end{abstract}

Results: We found that miR-205 and CHN1 were highly expressed in human cervical cancer tissue compared with paired normal cervical tissues. The CHN1 gene was shown to be targeted by miR-205 in HeLa cells. Interestingly, transfection with miR-205 mimic upregulated CHN1 mRNA and protein, while miR-205 inhibitor downregulated CHN1 in high-risk and human papilloma virus (HPV)-negative human cervical cancer cells in vitro,. These data suggested that miR-205 positively regulated the expression of CHN1. Furthermore, the miR-205 mimic promoted cell growth, apoptosis, migration, and invasion in high-risk and HPV-negative cervical cancer cells, while the miR-205 inhibitor blocked these biological processes. Knockdown of CHN1 obviously reduced the aggressive cellular behaviours induced by upregulation of miR-205, suggesting that miR-205 positively regulated CHN1 to mediate these cell behaviours during the development of cervical cancer. Furthermore, CHN1 was correlated with lymph node metastasis in clinical specimens.

(Continued on next page)

\footnotetext{
*Correspondence: hebox@263.net; syliu0098@126.com

${ }^{3}$ Reproductive Physiology Laboratory, National Research Institute for Family Planning, Beijing 100081, People's Republic of China

${ }^{4}$ School of Pre-clinical Sciences, Guangxi Medical University, Nanning 530021, People's Republic of China

Full list of author information is available at the end of the article
}

(c) The Author(s). 2020 Open Access This article is licensed under a Creative Commons Attribution 4.0 International License, which permits use, sharing, adaptation, distribution and reproduction in any medium or format, as long as you give appropriate credit to the original author(s) and the source, provide a link to the Creative Commons licence, and indicate if changes were made. The images or other third party material in this article are included in the article's Creative Commons licence, unless indicated otherwise in a credit line to the material. If material is not included in the article's Creative Commons licence and your intended use is not permitted by statutory regulation or exceeds the permitted use, you will need to obtain permission directly from the copyright holder. To view a copy of this licence, visit http://creativecommons.org/licenses/by/4.0/. The Creative Commons Public Domain Dedication waiver (http://creativecommons.org/publicdomain/zero/1.0/) applies to the data made available in this article, unless otherwise stated in a credit line to the data. 
(Continued from previous page)

Conclusions: Our findings showed that miR-205 positively regulated CHN1 to mediate cell growth, apoptosis, migration, and invasion during cervical cancer development, particularly for high-risk HPV-type cervical cancer. These findings suggested that dysregulation of miR-205 and subsequent abnormalities in CHN1 expression promoted the oncogenic potential of human cervical cancer.

Keywords: Cervical cancer, microRNA-205, a1-chimaerin, Migration, Invasion, Cancer gene

\section{Background}

Cervical cancer is one of the most commonly diagnosed cancer and the leading causes of cancer-related death in women worldwide $[1,2]$. However, despite the prevalence of this disease, therapeutic strategies are not sufficient, and patients with advanced disease are faced with poor outcomes.

MicroRNAs (miRNAs) are short (20-24 nt) noncoding RNAs that post-transcriptionally regulate gene expression in multicellular organisms by affecting both the stability and translation of mRNAs [3]. miRNAs regulate the expression of up to $60 \%$ of human genes [4] and generally reduce the protein expression of various targeted mRNAs [5]. Dysregulation of miRNA expression has been demonstrated in human cervical cancer tissues and cervical cancer cell lines; for example, miR-10a, $222,-196 a,-590,-361-5 p$, and -205 have been shown to promote cervical cancer cell growth, migration, and invasion [6-11], while miR-214, -26a, - 218 and -205 have been shown to inhibit cancer cell growth, migration, and invasion [12-15]. Moreover, studies of human cervical cancer have shown that dysregulation of miRNAs regulates various cancer-related genes $[8,9,16]$.

MiR-205 has been shown to have dual functions as an oncogenic miRNA or tumour-suppressive miRNA, depending on cell context $[5,17]$. Indeed, some studies have shown that $m i R-205$ serves as a tumoursuppressive miRNA by inhibiting the proliferation and invasion of cancer cells [12,18-21], while other studies have shown that miR-205 promotes tumour initiation, proliferation, and migration $[11,22]$. Additionally, miR205 positively regulates transcriptional activation of the tumour-suppressor genes interleukin (IL)-24 and IL-32 in prostate cancer [21] and directly regulates $I L-24$ in human KB oral cancer cells [23]. Interestingly, miR-205 expression is upregulated in human cervical cancer tissues and cell lines [11, 24, 25], and serum miR-205 levels are also increased in patients with cervical cancer [26]. Functionally, overexpression of $m i R-205$ has been shown to promote cell proliferation and migration by targeting the CYR61 and CTGF genes [11]; however, these genes have not been shown to be associated with cancer. Therefore, the mechanisms through which miR-205 mediates cervical cancer progression remain unknown.
n-Chimaerin (a1-chimaerin, CHN1) is a GTPaseactivating protein that exhibits activity toward the small GTPase Rac [27]. CHN1 may play a role in mediating cell motility [28, 29]. Moreover, bioinformatics prediction has shown that CHN1 is a putative target of miR205 and a potential cancer-associated gene listed in the Cancer Gene Census [30]. Therefore, we hypothesised that CHN1 might be regulated by $m i R-205$ and involved in the development and metastasis of human cervical cancer.

In the current study, we aimed to determine the mechanisms through which $m i R-205$ mediates the progression and development of cervical cancer. To this end, we analysed the relationships between $m i R-205$ and CHN1 expression and function in human cervical cancer tissues and cell lines. Our data supported that CHN1 and miR205 might be biomarkers of human cervical cancer metastasis and potential therapeutic targets in human cervical cancer.

\section{Methods}

Tissue samples and human cervical carcinoma cell lines Human cervical cancer tumours and adjacent nontumour tissues were obtained from Guangxi Medical University (China). The clinicopathological characteristics of the samples are summarised in Table 1. A cervical cancer tissue microarray was purchased from Shanghai Outdo Biotech Co. Ltd. (China). All patients provided informed consent for the use of their tissues before surgery. The study was approved by the Ethics Committee of the National Research Institute for Family Planning.

The human cervical carcinoma cell lines HeLa, SiHa, and C33A were purchased from the Cell Resource Center of Peking Union Medical College (Beijing, China) and cultured in Dulbecco's modified Eagle medium (DMEM) containing 10\% foetal bovine serum (FBS), 100 $\mathrm{IU} / \mathrm{mL}$ penicillin, and $10 \mathrm{mg} / \mathrm{mL}$ streptomycin. All cells were maintained at $37{ }^{\circ} \mathrm{C}$ in an atmosphere containing $5 \% \mathrm{CO}_{2}$.

In situ hybridisation of miR-205 with a digoxigenin (DIG)labelled LNA probe

The sections $(4 \mu \mathrm{m})$ of cervical cancer tissues and adjacent normal cervical tissues were treated with proteinase 
Table 1 Statistical analysis of clinical samples

\begin{tabular}{|c|c|c|c|c|c|c|c|}
\hline \multirow{2}{*}{$\begin{array}{l}\text { Clincal samples pathological } \\
\text { characteristics }\end{array}$} & \multirow[t]{2}{*}{$\mathrm{n}$} & \multirow{2}{*}{$\begin{array}{l}\text { CHN1 } \\
-\end{array}$} & \multicolumn{3}{|c|}{ CHN1 upregulated } & \multirow[t]{2}{*}{$P$} & \multirow{2}{*}{$\begin{array}{l}\text { Pearson } \\
\text { Chi-Square }\end{array}$} \\
\hline & & & + & ++ & +++ & & \\
\hline Tumor size $(\mathrm{cm})$ & & & & & & 0.660 & 1.597 \\
\hline$\leq 3$ & 18 & 2 & 9 & 4 & 3 & & \\
\hline$>3$ & 28 & 2 & 12 & 11 & 3 & & \\
\hline Differentiation grade & & & & & & 0.269 & 7.594 \\
\hline । & 2 & 1 & 1 & 0 & 0 & & \\
\hline$\|$ & 38 & 2 & 18 & 12 & 6 & & \\
\hline III & 6 & 1 & 2 & 3 & 0 & & \\
\hline Depth of invasion & & & & & & 0.962 & 0.290 \\
\hline$\leq 1 / 2$ muscular layer & 16 & 1 & 8 & 5 & 2 & & \\
\hline$>1 / 2$ muscular layer & 30 & 3 & 13 & 10 & 4 & & \\
\hline Tissue microarray lymphatic metastasis & & & & & & 0.008 & 11.895 \\
\hline Absent & 23 & 2 & 15 & 4 & 2 & & \\
\hline Present & 25 & 0 & 7 & 7 & 11 & & \\
\hline
\end{tabular}

$-(0 \leq$ HSCORE $<75) ;+(75 \leq$ HSCORE $<150) ;++(151 \leq$ HSCORE $<225) ;+++(225 \leq$ HSCORE $\leq 300)$

$\mathrm{K}(20 \mathrm{mg} / \mathrm{mL})$ for $15 \mathrm{~min}$ and refixed in 4\% PFA for 15 min. After acetylation with $0.25 \%$ acetic anhydride in $0.1 \mathrm{M}$ triethanolamine ( $\mathrm{pH}$ 8.0) for $10 \mathrm{~min}$, sections were prehybridised with hybridisation buffer (Roche, Mannheim, Germany) at $40^{\circ} \mathrm{C}$ for $2 \mathrm{~h}$ and then hybridised with a DIG-labelled LNA-miR-205 probe (5'-CAG(+ A)C(+T)CCGG(+T)GGAA(+T)GA(+A)GGA-DIG-3') at $40^{\circ}$ Covernight. The sections were then incubated in buffer containing anti-DIG-antibody (Roche) $2 \mathrm{~h}$ at $37^{\circ} \mathrm{C}$, followed by staining with NBT and BCIP (Promega, Madison, WI, USA). Samples were viewed under a Nikon TE 2000-U microscope (Nikon, Tokyo, Japan).

\section{Immunohistochemical analysis of CHN1}

Sections $(4 \mu \mathrm{m})$ of cervical cancer tissues and adjacent normal cervical tissues were dewaxed and rehydrated, followed by an antigen retrieval procedure (citrate buffer, $\mathrm{pH} 6.0$; $95^{\circ} \mathrm{C}$ heat for $\left.15 \mathrm{~min}\right)$. For $\mathrm{CHN} 1$ staining, the sections were soaked in $3 \% \mathrm{H}_{2} \mathrm{O}_{2}$ for $15 \mathrm{~min}$ and incubated overnight at $4{ }^{\circ} \mathrm{C}$ with rabbit anti-CHN1 antibodies (12048-1-AP; 1:150; Proteintech, USA). Matched rabbit nonimmune IgG was used as a negative control. The sections were then treated with horseradish peroxidase (HRP)-conjugated anti-rabbit IgG (PV-6001; Zymed Laboratories, China) and incubated for $20 \mathrm{~min}$ at $37^{\circ} \mathrm{C}$; the proteins were visualised with $3,3^{\prime}$-diaminobenzidine tetrahydrochloride and counter stained with hematoxylin. Immunohistochemical analysis of CHN1 was carried out according to the "HSCORE" method [31]; an HSCORE of 75 or greater was considered positive. The specimens were analysed by two observers who were unaware of the patients' clinical outcome. Discrepancies between the observers were found in $<10 \%$ of the slides examined, and consensus was reached on further review.

\section{Transfection and cotransfection}

The miR-205 mimic, miR-205 inhibitor, corresponding negative control (NC), and siRNA duplex against human CHN1 were designed and synthesised by GenePharma (GenePharma Co., Ltd., Shanghai, China). Their sequences are shown in Table 2. Transient transfection was performed using lipofectamine 2000 reagent (Invitrogen, Carlsbad, CA, USA) according to the manufacturer's instructions.

\section{Plasmid constructs and dual-luciferase activity assay} The 3' untranslated regions (UTRs) of the human CHN1 gene (NM_001025201.2) were amplified by polymerase chain reaction (PCR) from human genomic DNA, cloned into the Sbfl and NheI site of the pmirGLO Dual-Luciferase miRNA Target Expression Vector (Promega), checked for orientation, and sequenced; the resulting plasmid was named pmirGLO-CHN1-wt. PCR primers used to amplify the CHN1 3'UTR are shown in Table 2. Site-directed mutagenesis of the miR-205 target site in the CHN1 3'UTR was carried out using an Easy Mutagenesis System (Transgen, China), with pmirGLOCHN1-wt as a template; the resulting plasmid was named pmirGLO-CHN1-mut.

Next, $5 \times 10^{4}$ cells were seeded in each well of a 48 well plate at $24 \mathrm{~h}$ before transfection. For reporter assays, the cells were transiently cotransfected with $0.25 \mu \mathrm{g}$ wild-type (WT) or mutant reporter plasmid and 7.5 pmol NC or miR-205 mimic using Lipofectamine 2000. At $48 \mathrm{~h}$ after cotransfection, Firefly and Renilla luciferase activities were measured consecutively using Dual 
Table 2 The sequences of siRNA, miRNA and primer used in this study

\begin{tabular}{|c|c|}
\hline Gene & Sequence \\
\hline \multirow[t]{2}{*}{ CHN1 3'UTR } & Forward: 5'-(C)TTGAGGGGAAAAGAAATG-3' \\
\hline & Reverse: 5'-ATGTAACAGCCAGAGGTGC-3' \\
\hline \multirow[t]{2}{*}{ CHN1-mut } & $\begin{array}{l}\text { Forward: 5'-AGAAATGTTTTACAGGCTGGCCG } \\
\text { ATGTIITATAG-3' }\end{array}$ \\
\hline & $\begin{array}{l}\text { Reverse: 5'-CGGCCAGCCTGTAAAACATTTCTT } \\
\text { TTCCCCTCA-3' }\end{array}$ \\
\hline \multirow[t]{3}{*}{ Has-miR-205 } & $\begin{array}{l}\text { RT-205: 5'-GTCGT ATCCA GTGCA GGGTC CG } \\
\text { AGG TATTC GCACT GGATA CGACC AGACT-3' }\end{array}$ \\
\hline & Forward: 5'-AATTGTCCTTCATTCCACCGG-3' \\
\hline & Reverse: 5'-GTGCAGGGTCCGAGGT-3' \\
\hline \multirow[t]{2}{*}{ Human U6 } & Forward: 5'-CGCTTCGGCAGCACATATAC-3' \\
\hline & Reverse: 5'-TTCACGAATTTGCGTGTCAT-3' \\
\hline \multirow[t]{2}{*}{ CHN1 } & Forward: 5'-GGAGCTACCTCATCCGGGAG-3' \\
\hline & Reverse: 5'-TGTGTCTCTTTCAGGACTGGCA-3' \\
\hline \multirow[t]{2}{*}{ GAPDH } & $\begin{array}{l}\text { Forward: 5'-GGTCTTACTCCTTGG AGGCCA } \\
\text { TGTG-3' }\end{array}$ \\
\hline & Reverse: 5'-ACCTAACTACATCGTTACATGTT-3' \\
\hline LNA-miR-205 probe & $\begin{array}{l}5^{\prime}-C A G(+A) C(+T) C C G G(+T) G G A A(+T) \\
\text { GA(+A)GGA-Dig-3' }\end{array}$ \\
\hline Hsa-miR-205 & 5'-UCCUUCAUUCCACCGGAGUCUG-3' \\
\hline Hsa-miR-205 mimic & 5'-GACUCCGGUGGAAUGAAGGAUU-3' \\
\hline MircoRNA inhibitor NC & 5'-CAGUACUUUUGUGUAGUACAA-3' \\
\hline Hsa-miR-205 inhibitor & 5'-CAGACUCCGGUGGAAUGAAGGA-3' \\
\hline Negative control & 5'-UUCUCCGAACGUGUCACGUTT-3' \\
\hline si-CHN1 & 5'-GGCUUGAUUACUCUCUAUATT-3' \\
\hline
\end{tabular}

Luciferase Assays (Promega) according to the manufacturer's instructions. Three independent experiments were performed.

\section{qRT-PCR}

Total RNA extraction and qRT-PCR experiments were performed for analysis of gene expression as follows. Briefly, RNA was isolated using TRIzol reagent (Invitrogen). For cDNA synthesis, approximately $2 \mu \mathrm{g}$ of total RNA was used for reverse transcription with oligo$(\mathrm{dT})_{18}$ primers using moloney murine leukaemia virus (M-MLV) reverse transcriptase (TaKaRa Bio, Otsu, Japan). The specific forward primer for miR-205 was designed by GenePharma based on the miRNA sequence from the miRbase database.

qRT-PCR was performed with an ABI Prism 7700 Sequence Detector System (PE Applied Biosystems, Foster City, CA, USA) using SYBR Premix Ex Taq II (TaKaRa Bio) and specific primers for each gene. To control for uniform amount of input RNA template, mRNA and miRNA expression results were normalised to the expression level of the internal control gene GAPDH or U6 snRNA, respectively. Thermal cycling conditions were as follows: an initial activation cycle at $95^{\circ} \mathrm{C}$ for 30 $\mathrm{s}$, followed by 40 cycles of denaturation $\left(95^{\circ} \mathrm{C}\right.$ for $\left.10 \mathrm{~s}\right)$, annealing, and amplification $\left(60^{\circ} \mathrm{C}\right.$ for $\left.30 \mathrm{~s}\right)$. The final amplification products were verified by agarose gel electrophoresis for treatment samples and negative controls. The primer sequences are shown in Table 2. Each sample was assayed in triplicate. To compare the expression levels among different samples, relative quantification was achieved using the $2^{-\Delta \Delta \mathrm{Ct}}$ approach, in which $\Delta \Delta \mathrm{Ct}$ is the calibrated $\mathrm{Ct}$ value.

\section{Western blot analysis}

Total protein lysates were obtained using RIPA lysis buffer supplemented with $1 \mathrm{mM}$ PMSF, protease inhibitor cocktail, $1 \mathrm{mM} \mathrm{Na} \mathrm{VO}_{4}$, and $10 \mathrm{mM} \mathrm{NaF}$ (Sigma Aldrich, St. Louis, MO, USA). The protein concentrations in extracts were determined by colorimetric BCA protein assays (Thermo Scientific, USA). Proteins were separated by SDS-polyacrylamide gel electrophoresis (PAGE) on 10\% Tris-glycine gels (Amresco, Solon, OH, USA) and then transferred onto polyvinylidene fluoride membranes (Millipore, Billerica, MA, USA). Membranes were blocked for $1 \mathrm{~h}$ at RT with TBST $(50 \mathrm{mM}$ Tris$\mathrm{HCl}, 150 \mathrm{mM} \mathrm{NaCl}$, and $0.1 \%$ [v/v] Tween-20) containing $5 \%(\mathrm{w} / \mathrm{v})$ nonfat dried milk and were subjected to immunoblotting with antibodies to CHN1 (12048-1-AP; Proteintech) and $\beta$-actin (CoWin, Beijing, China).

\section{Cell proliferation assay}

The proliferation of HeLa, $\mathrm{SiHa}$, and C33A cells was estimated with a Cell Counting Kit-8 (CCK-8; Dojindo Laboratories, Japan) according to the manufacturer's instructions following transfection with $m i R-205$ mimic, NC, miR-205 inhibitor, or inhibitor NC, with five wells for each treatment. The experiment was repeated three times, and the results are described as the ratio of the absorbance at $450 \mathrm{~nm}$ for the $m i R-205$ mimic or inhibitor to that of the corresponding control.

\section{Flow cytometry analysis}

Cell apoptosis was analysed using flow cytometry analysis with an Alexa Fluor 488 annexin V/Dead Cell Apoptosis Kit (Invitrogen). Samples containing $5 \mu \mathrm{L}$ Alexa Fluor 488 annexin $\mathrm{V}$ and $1 \mu \mathrm{L}$ of $100 \mu \mathrm{g} / \mathrm{mL}$ propidium iodide (PI) were assayed to determine the phosphatidylserine (PS) exposure on the outer leaflet of the plasma membrane. After incubation for $15 \mathrm{~min}$ at in a light-protected area, the specimens were quantified by flow cytometry (BD Biosciences, San Jose CA, USA). Each treatment was repeated twice, and the experiment was repeated three times. 


\section{In vitro migration and invasion assays}

$\mathrm{HeLa}, \mathrm{SiHa}$, and C33A cells were transfected with the miR-205 mimic, NC, miR-205 inhibitor, or inhibitor NC. Transfected cells were harvested and subjected to the following assays at $48 \mathrm{~h}$ after transfection. For migration assays, the transfected cells $\left(0.5 \times 10^{6}\right.$ cells $\left./ \mathrm{mL}\right)$ were seeded in the top of a chamber containing a membrane with 8.0- $\mu \mathrm{m}$ pores (Corning Costar Corp., Cambridge, MA, USA). Following a $12-18 \mathrm{~h}$ incubation period, cells that passed through the membrane were fixed and stained with hematoxylin. Cells were scraped and removed from the top of chamber. Membranes were mounted on cover slides, and cells were counted. Cell migration was quantified by counting the number of cells passing through the pores from five different randomly selected fields of view per sample at $100 \times$ magnification under a microscope. For invasion assays, Matrigel (BD Biosciences) diluted to $1 \mathrm{mg} / \mathrm{mL}$ in serumfree cold cell culture medium was added to the top of a chamber containing a membrane with $8.0-\mu \mathrm{m}$ pores and incubated at $37^{\circ} \mathrm{C}$ overnight until the matrigel solidified. Analysis was then carried out as described above. Samples were viewed under a Nikon TE 2000-U microscope (Nikon, Tokyo, Japan).

\section{Statistical analysis}

Data are expressed as means \pm SEMs. The statistical significance of the quantitative data was assessed by paired Student's t-tests, and clinical correlations were analysed by Pearson chi-square test. $P<0.05$ was considered to be statistically significant.

A
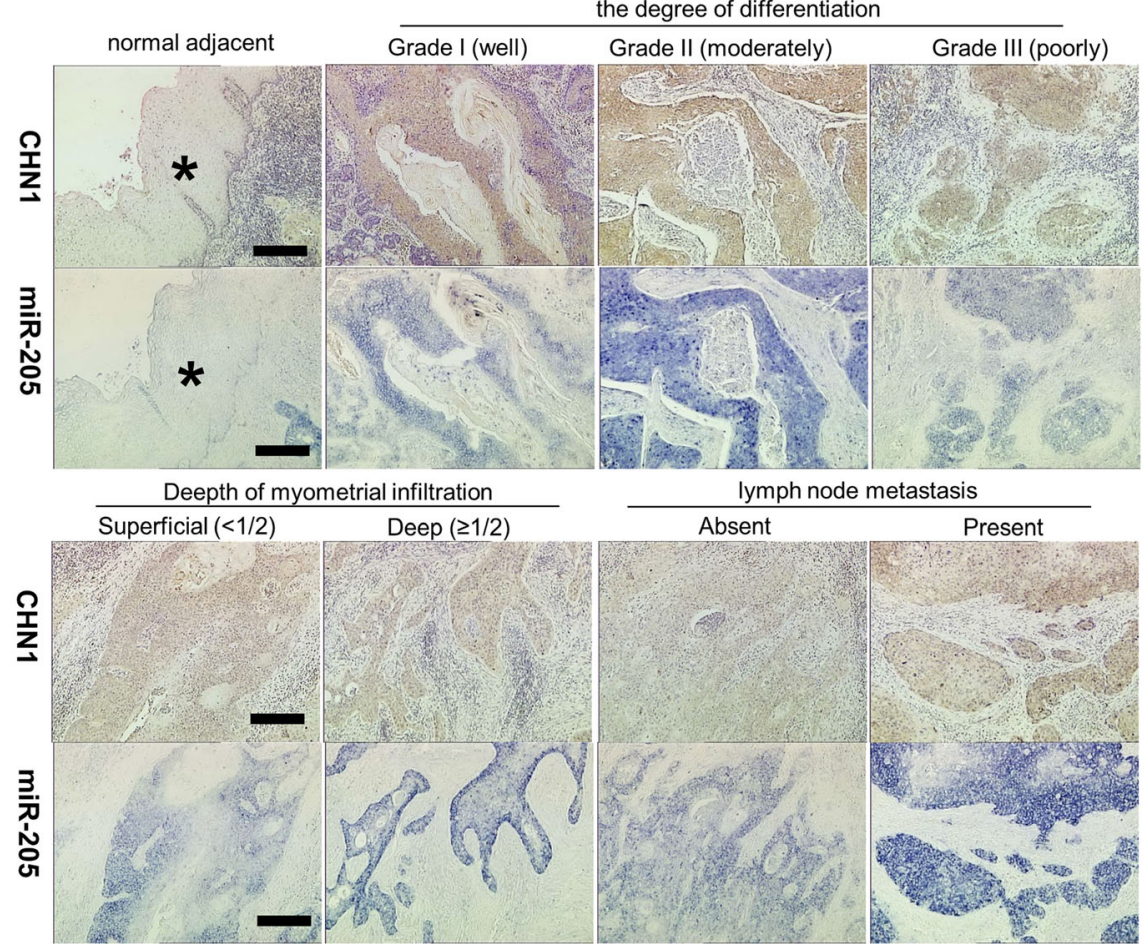

B

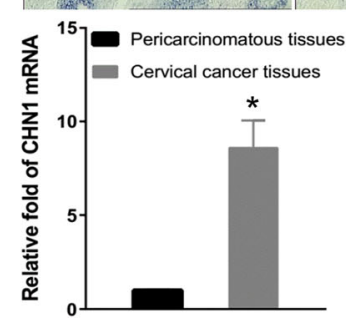

Fig. 1 The expression of miR-205 and CHN1 in cervical cancer. a:Distribution and expression of miR-205 and CHN1 protein in human cervical tissues. The expression and localisation of miR-205 in human cervical cancer tissues and adjacent normal cervical tissues was determined using in situ hybridisation. The stain was developed with BCIP/NBT. The expression and localisation of CHN1 protein in human cervical cancer tissues and adjacent normal cervical tissues was analysed by immunohistochemistry. The stain was developed with DAB, and nuclei were stained with hematoxylin. *Normal cervical epithelial tissue adjacent to carcinoma. Bar $=200 \mu \mathrm{m}$. b: The expression of CHN1 mRNA in the cervical cancer tissues and the para-carcinoma tissues was detected by qRT-PCR. GAPDH served as an internal reference gene. * $P<0.05$ 


\section{Results}

miR-205 and CHN1 expression levels were upregulated in human cervical cancer tissues

Expression patterns of $m i R-205$ were analysed by in situ hybridisation in 46 pairs of human cervical cancer tissues and adjacent normal cervical tissues. As shown in Fig. 1, the expression of $m i R-205$ was high in human cervical cancer tissues, but low or undetectable in normal cervical epithelium and noncancerous cervical stratified epithelium. Then, miR-205 target genes were searched using bioinformatic prediction of potential miR-205 binding sites with PicTar, Targetscan, miRanda, and miRBase programs, to elucidate the molecular mechanisms through which miR-205 functioned in human cervical carcinogenesis. Among the identified targets, CHN1 attracted our attention for following reasons: (i) there were two binding sites for miR-205 in the 3'UTR of CHN1, one of which was highly conserved among different species (Fig. 2a); and (ii) CHN1 has been reported to be a cancer-associated gene [26] involved in cell migration and cancer cell motility $[24,28]$. CHN1 mRNA expression was elevated in the cervical cancer tissues than in the adjacent tissues of cancer (Fig. 1b). CHN1 protein expression was abnormally increased in tumour cell masses/cords, but was barely detectable or undetectable in normal cervical epithelium and noncancerous cervical stratified epithelium (Fig. 1a). Notably, in locations where $m i R-205$ expression was enhanced, CHN1 was also increased; conversely, when miR-205 expression was decreased, CHN1 was also decreased. These data suggested that miR-205 and CHN1 were synchronously upregulated in human cervical tumours, which was contradictory to our expectations.

\section{Validation of $\mathrm{CHN} 1$ as target of miR-205 in human cervical cancer cells}

According to software-based prediction, the first seven nucleotides at the $5^{\prime}$-end of $m i R-205$ were complementary to nucleotides $36-43$ of the 3'UTR of the CHN1

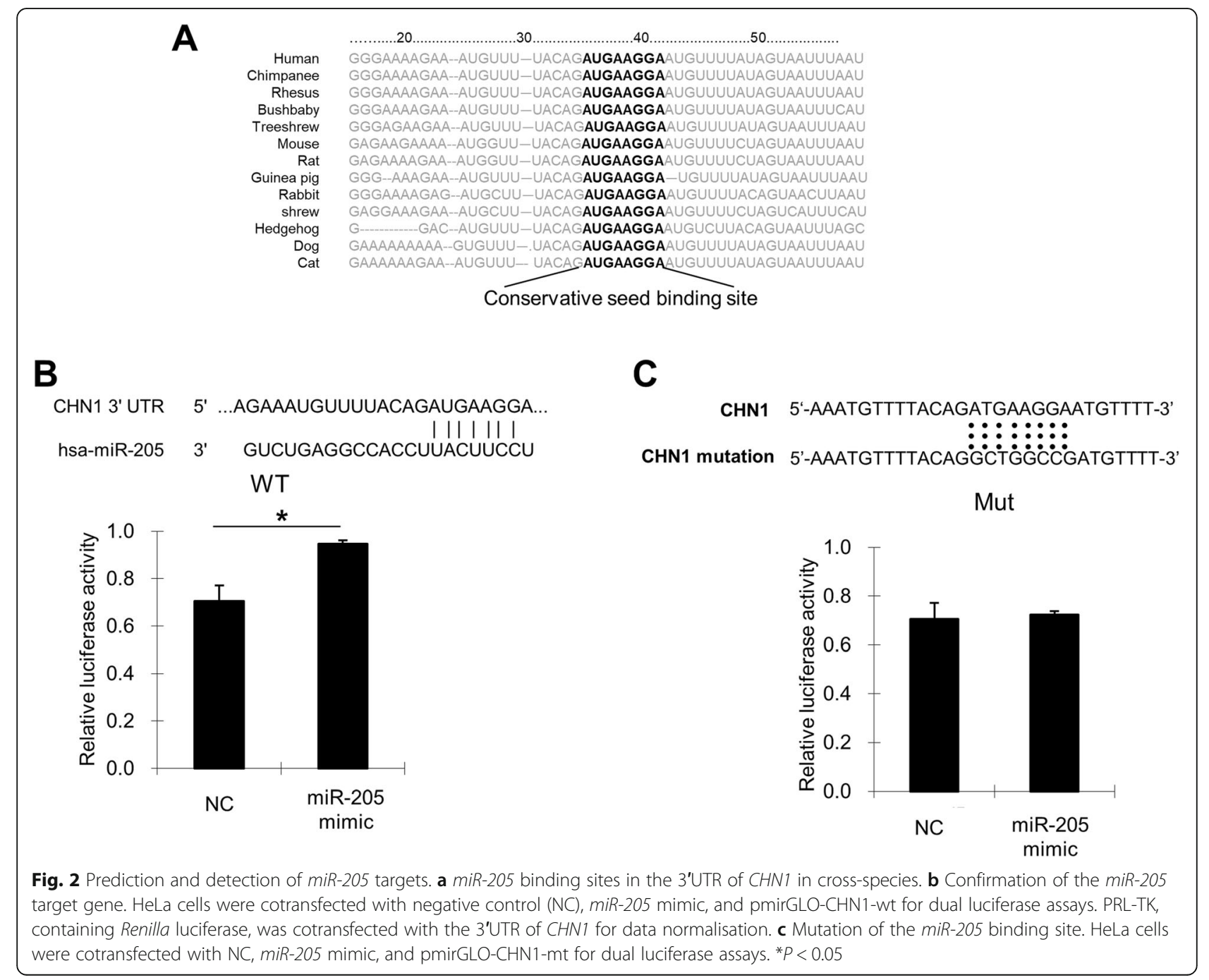


gene (seed sequence; Fig. 2b). To validate whether CHN1 was a target of miR-205, HeLa cells were cotransfected with pmirGLO-CHN1-wt and miR-205 mimic or $\mathrm{NC}$. Compared to the $\mathrm{NC}$, transfection with the miR205 mimic increased the relative luciferase activity of the pmirGLO-CHN1-wt construct $(P<0.05$; Fig. $2 b)$. Moreover, cotransfection of HeLa cells with a construct harbouring a mutated seed sequence and the $\mathrm{NC}$ or miR-205 mimic revealed that the miR-205 mimic could not increase the relative luciferase activity of the pmirGLO-CHN1-mut construct in the absence of the WT seed sequence (Fig. 2c). These results strongly supported that CHN1 was a target of miR205 in HeLa cells.
miR-205 positively regulated the expression of CHN1 in human cervical cancer cells in vitro

As shown in Fig. 3a and b, the expression levels of miR-205 and CHN1 mRNA were higher in C33A cells and lower in $\mathrm{SiHa}$ cells than those in HeLa cells. The results of western blotting analysis of $\mathrm{CHN} 1$ protein were consistent with these results (Fig. 3c, Supplementary Figure 1). Thus, overall, these results demonstrated that high miR-205 expression was associated with high CHN1 expression, and vice versa, in the cervical cancer cell lines. The levels of $m i R-205$, CHN1 mRNA, and CHN1 protein were significantly increased in cells transfected with miR-205 mimic compared with those in cells transfected with NC

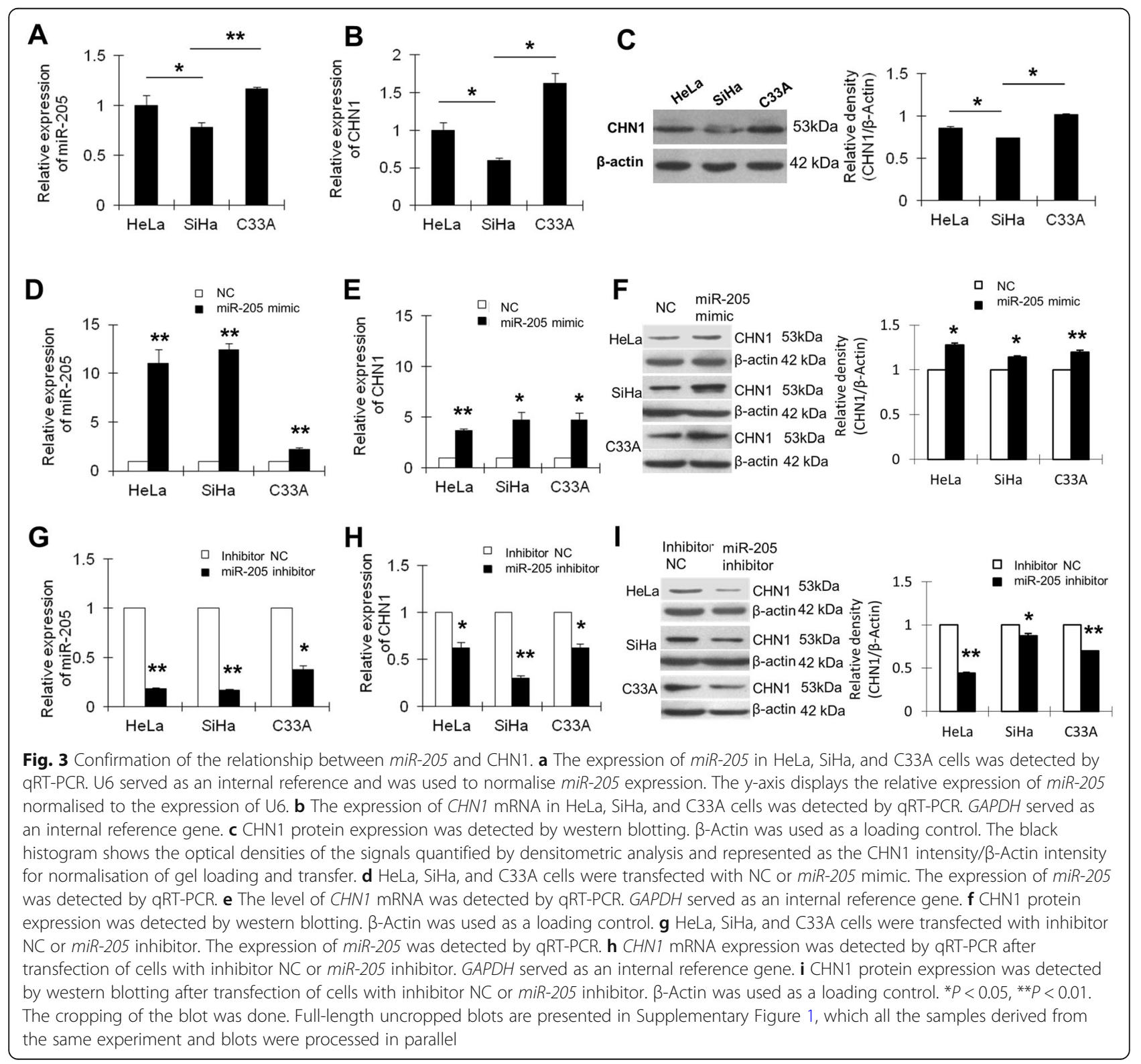


(Fig. 3d-f, Supplementary Figure 1). Conversely, the levels of miR-205, CHN1 mRNA, and CHN1 protein were reduced in cells transfected with miR-205 inhibitor, in comparison to those in cells transfected with inhibitor NC (Fig. 3g-i, Supplementary Figure 1). These results demonstrated that miR-205 positively and directly regulated the expression of CHN1 in human cervical cancer cells.

miR-205-dependent expression of CHN1 was involved in the proliferation, apoptosis, migration, and invasion of human cervical cancer cells in vitro

The functions of miR-205-dependent CHN1 expression in the pathological processes of cervical cancer cells were examined. At $48 \mathrm{~h}$ after transfection, compared to those in cells transfected with NC (Fig. 4a), the relative proliferation rates of $\mathrm{HeLa}, \mathrm{SiHa}$, and C33A cells transfected with $m i R-205$ mimic were increased by about 13.38\% $(P<0.05), 11.77 \%(P<0.05)$, and $14.28 \%(P<$ $0.05)$, respectively. Conversely, the relative proliferation rates in $\mathrm{HeLa}, \mathrm{SiHa}$, and $\mathrm{C} 33 \mathrm{~A}$ cells transfected with miR-205 inhibitor were decreased by about $21.72 \%(P<$ $0.05), 17.56 \%(P<0.05)$, and $18.62 \%(P<0.05)$, respectively, in comparison with those in cells transfected with inhibitor NC (Fig. 4a). These results showed that overexpression of $m i R-205$ significantly promoted cervical cancer cell proliferation, while downregulation of miR-205 suppressed cervical cancer cell proliferation.

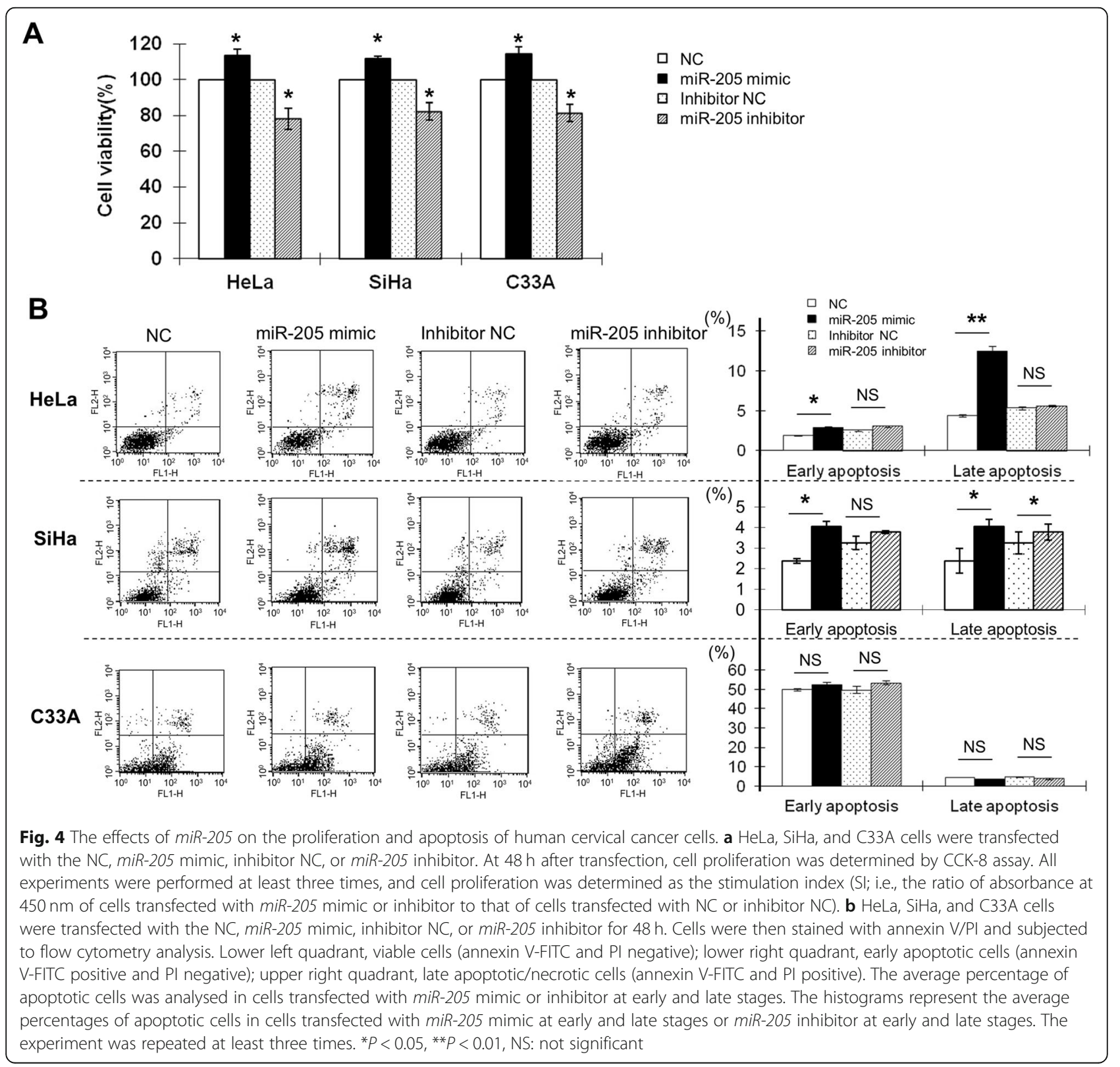


Analysis of apoptosis revealed that transfection with the miR-205 mimic significantly increased early apoptosis in HeLa $(P<0.05)$ and SiHa cells $(P<0.05)$, but not in C33A cells $(P>0.05)$. Late apoptosis was also enhanced in HeLa $(P<0.01)$ and SiHa cells $(P<0.05)$, but not in C33A cells $(P>0.05)$, as compared with that in cells transfected with NC (Fig. 4b). Interestingly, transfection with miR-205 inhibitor did not affect early apoptosis in any of the three cell lines, while late apoptosis was increased in SiHa cells $(P<0.05)$, but not in HeLa or C33A cells $(P>0.05)$, as compared with those in cells transfected with inhibitor NC (Fig. 4b).

The migration capacity of HeLa, SiHa, and C33A cells transfected with the miR-205 mimic was significantly higher than that in cells transfected with NC (HeLa, $P<$ 0.01; SiHa and C33A, $P<0.05$; Fig. 5). Similarly, the migration capacity was decreased in $\mathrm{HeLa}, \mathrm{SiHa}$, and C33A cells transfected with miR-205 inhibitor, as compared with that in cells transfected with inhibitor NC $(P<0.05$ for all cell lines; Fig. 5). Additionally, the invasive ability of HeLa and SiHa cells (HeLa, $P<0.05$; SiHa, $P<0.01$ ), transfected with the miR-205 mimic was evidently enhanced, but C33A cells $(P>0.05)$, as compared with that in cells transfected with the NC (Fig. 6). Conversely, transfection with the miR-205 inhibitor reduced invasive ability in HeLa and SiHa cells (HeLa and SiHa, $P<0.05$ ), but not in C33A cells $(P>0.05)$, compared with that in cells transfect with the inhibitor NC (Fig. 6). These results suggested that miR-205 expression might be closely associated with the metastasis of cervical cancer cells.
To further examine whether miR-205 may have oncogenic roles through targeting of $\mathrm{CHN} 1$, the effects of CHN1 knockdown on miR-205-mediated cell behaviours were investigated. Importantly, transfection with siCHN1 significantly downregulated CHN1 mRNA and protein expression $(P<0.05$; Fig. $7 \mathrm{a}$ and b, Supplementary Figure 2). Functional analysis revealed that knockdown of $\mathrm{CHN} 1$ reduced cell viability, migration, and invasion $(P<0.05$ for all) in SiHa cells (Fig. $7 \mathrm{c}$ and e). In addition, knockdown of CHN1 using si-CHN1 decreased the rate of apoptosis in SiHa cells (Fig. 7d). Finally, cotransfection of SiHa cells with si-CHN1 and the miR205 mimic, resulted in lower capacity for proliferation, migration, invasion, and apoptosis $(P<0.05$ for all $)$ than those in cells transfected with the miR-205 mimic (Fig. 7c-e). These results demonstrated that the effects of miR-205 overexpression on cell growth and metastasis were partially attenuated by knockdown of CHN1.

\section{CHN1 overexpression was associated with metastasis in human cervical cancer}

The immunohistochemical analysis of CHN1 of $46 \mathrm{hu}$ man cervical cancer samples were performed, to investigate the relationship between $\mathrm{CHN} 1$ overexpression and the clinical characteristics of human cervical cancer. The results showed that upregulation of $\mathrm{CHN1}$ was not significantly associated with tumour size $(P=0.660)$, differentiation grade $(P=0.269)$, or depth of invasion $(P=$ 0.962), suggesting that upregulation of $\mathrm{CHN} 1$ was a common characteristic in human cervical cancer

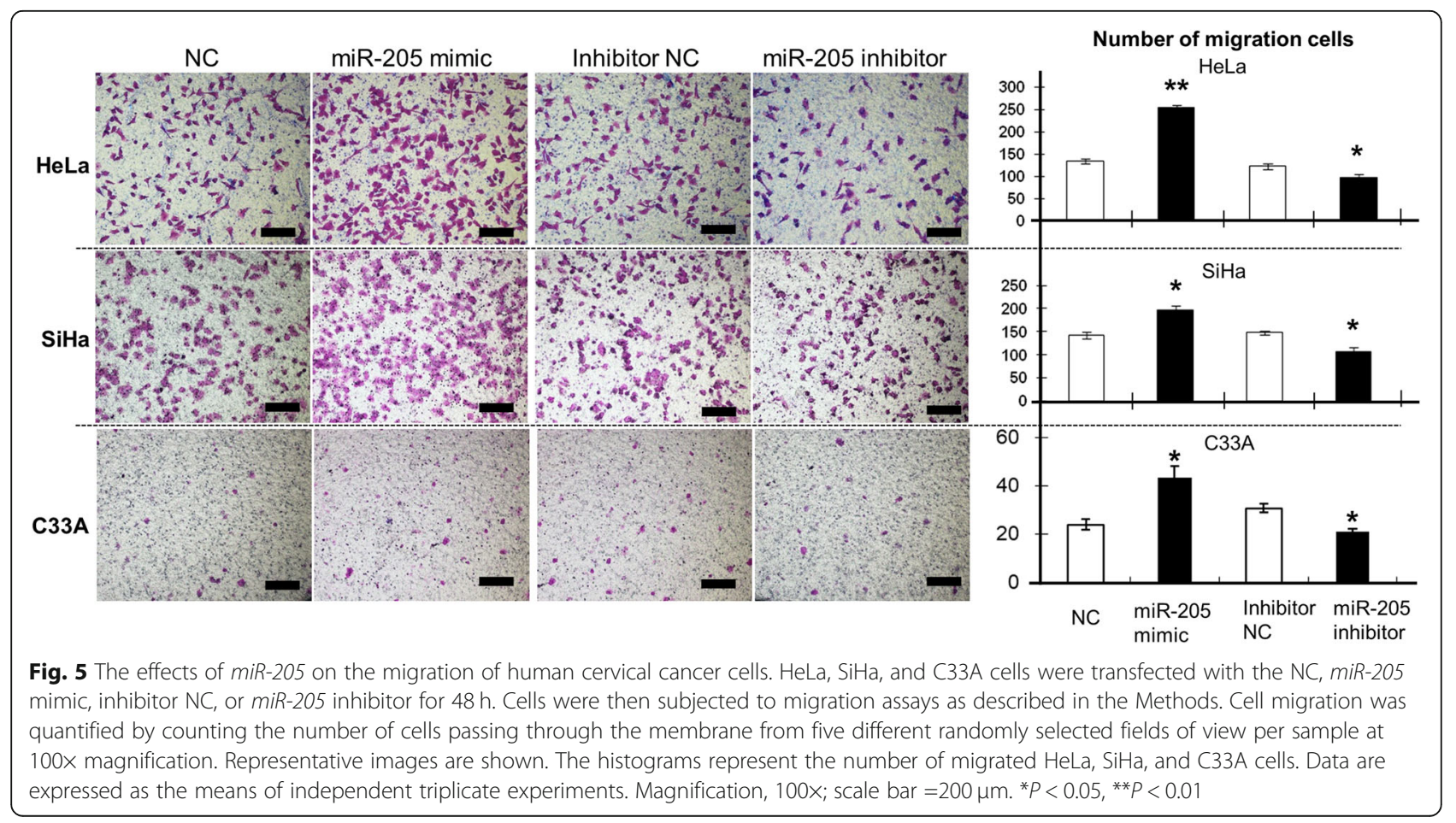




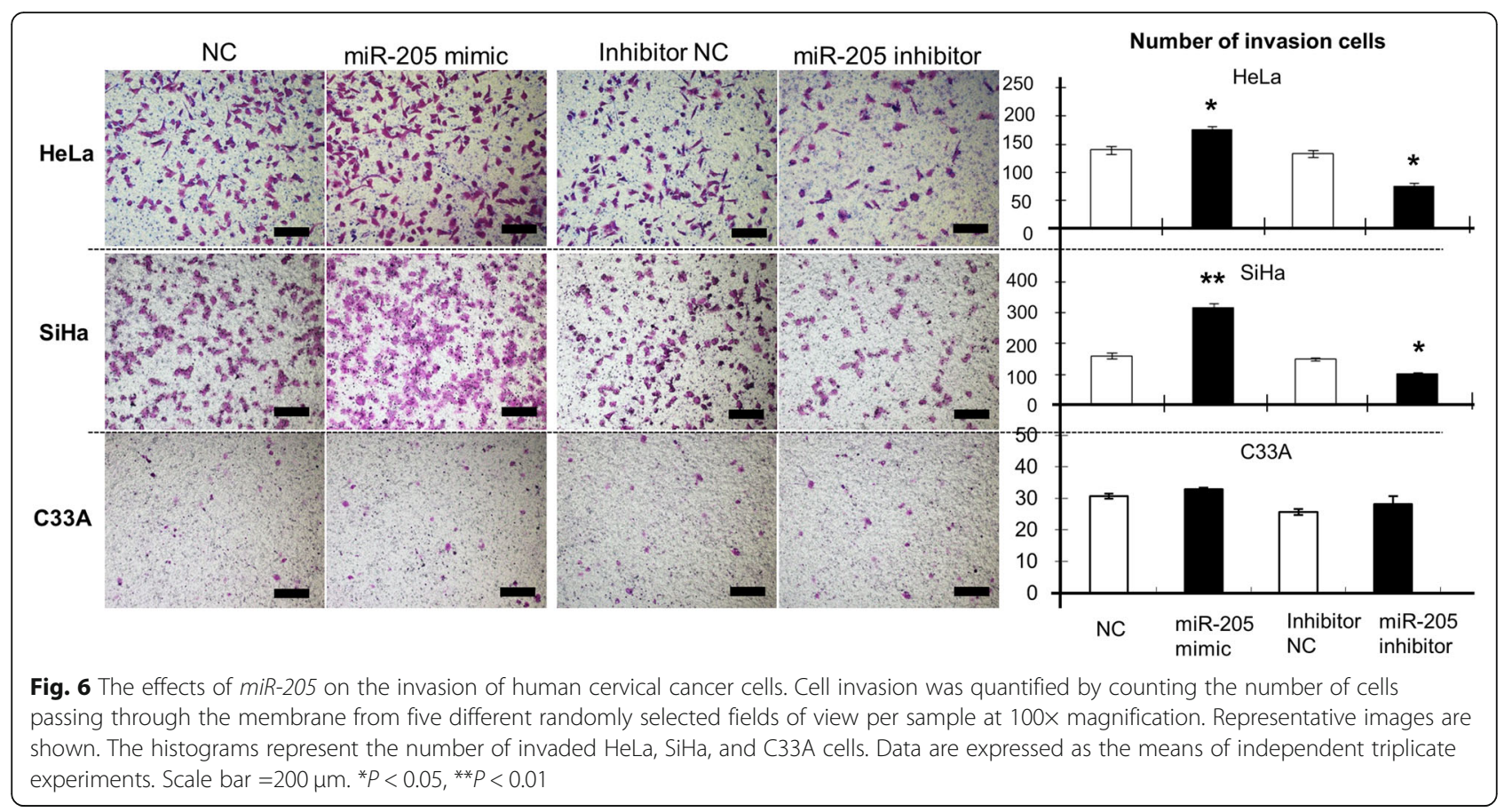

(Table 1.). Therefore, CHN1 may be a novel biomarker for the clinical diagnosis of carcinogenesis of normal cervical epithelium.

To further analyse the differences between CHN1 expression and metastasis of cervical tumours, we investigated the expression of $\mathrm{CHN} 1$ in a microarray of cervical cancer tissues with or without lymph node metastasis. We found that the intensity of CHN1 expression was significantly associated with lymph node metastasis of cervical cancer $(P=0.008)$.

\section{Discussion}

In this study, for the first time, we demonstrated that $m i R-205$ positively regulated the expression of CHN1 in cervical cancer and that miR-205-dependent upregulation of CHN1 promoted the proliferation, migration, and invasion of cervical cancer.

In previous studies, $m i R-205$ has been shown to have dual roles in cancer development, acting as either a tumour suppressor or oncogene. For example, miR-205 expression was reduced in melanoma [32], oesophageal cancer [33], and oesophageal squamous cell carcinoma [34], but increased in endometrial adenocarcinoma [35], head and neck squamous cell carcinoma cell lines [36], and ovarian cancer [37]. In cervical cancer patients, serum $m i R$-205 was significantly upregulated, compared with that in healthy donors, and a high level of $m i R-205$ expression was correlated with poor tumour differentiation, lymph node metastasis, and increased tumour stage [26]. However, miR-205 was downregulated in cervical intraepithelial neoplasia and cervical squamous cell carcinoma [38]. In this study, we found that miR-205 was highly expressed in cervical cancer samples compared to normal cervical tissues, demonstrating that miR-205 functioned as an oncogene in this context.

$M i R-205$ functions by regulating the expression of a variety of target genes. Contradictory to the traditional negative regulation observed in miRNAs, we found that miR-205 positively regulated CHN1. Unlike the general mechanism of miRNA, some previous studies have shown that miRNAs can positively regulate target genes [21, 23, 39]. Specifically, early in 2007, the study published in Science showed that human miR-369-3 directed association of Argonaute (AGO) and fragile X mental retardation-related protein 1 (FXR1) with the AU-rich elements (AREs) to switch from repression to activation on the translation of target gene mRNAs [39]. Further, $m i R-205$ in the $\mathrm{KB}$ oral cancer cells induced tumour suppressor gene IL-24 mRNA and protein by targeting its promoter [23]. Moreover, in prostate cancer, $m i R-205$ also upregulated the tumour suppressor genes $I L-24$ and IL-32 mRNA and protein by targeting their promoters [21]. In our study, miR-205 induced the expression of CHN1 mRNA and protein by binding to the 3'UTR of CHN1. However, the target region observed in this study were different from that reported in previous studies. Further studies are needed to fully elucidate the mechanisms through which some miRNAs positively regulate target genes.

Cancer cell proliferation, migration, and invasion are characteristics of cancer development and essential for invasion of cancer cells into the lymph and blood vessels 


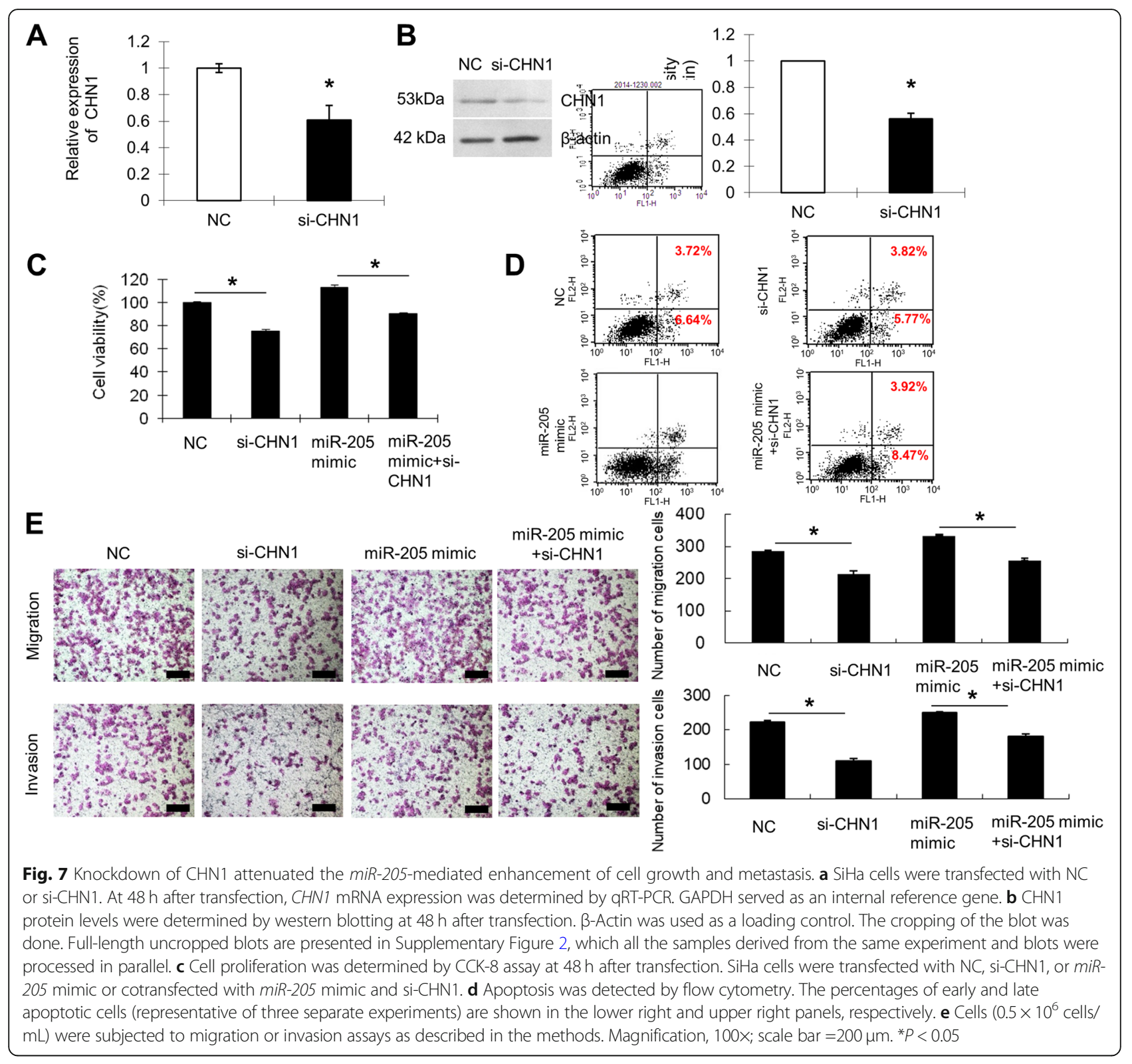

for development of metastatic lesions. Here, we found that $m i R-205$ was expressed in $\mathrm{HeLa}\left(\mathrm{HPV}^{+} 8^{+}\right)$, SiHa $\left(\mathrm{HPV} 16^{+}\right)$, and C33A $\left(\mathrm{HPV}^{-}\right)$cells, contrary to a previous study showing that miR-205 was not expressed in these three cell lines [25]. We also found that miR-205 was vital for cell proliferation, invasion, and migration in the different of HPV types. These results were consistent with a previous study which showed miR-205 could promote cell proliferation and migration [11]. MiR205 was also involved in cellular invasion in other types of cancer [34, 40]. Here, for the first time, we found that miR-205 exhibited a novel function in cell invasion of cervical cancer. Additionally, our studies showed that knockdown of CHN1 in $\mathrm{SiHa}$ cells blocked cancer-associated biological processes, further highlighting the importance of miR-205 and miR-205dependent expression of $\mathrm{CHN} 1$ in cervical cancer development.

The expression levels and functions of $m i R-205 / \mathrm{CHN} 1$ varied in cervical cancer cell lines exhibiting different HPV types which are vital to cancer development. For example, miR-205 was highly expressed in HPV-negative C33A cells, but did not function in cell apoptosis and invasion, as was observed for HeLa and SiHa cells (highrisk $\mathrm{HPV} 18^{+}$and $\mathrm{HPV} 16^{+}$cell lines, respectively). These data improved our understanding of the importance of HPV, particularly high-risk HPV infection, in the development of cervical cancer.

The interaction between HPV and miRNAs during carcinogenesis may be used to explain the difference of 
$m i R-205 / C H N 1$ expression and function in the different cell lines. For instance, some miRNAs localise the sites of HPV insertion, while proteins encoded by HPV can act on miRNAs. Additionally, E family viral proteins of HPV modulate the expression of DNA methyltransferases to regulate gene expression [41]. Therefore, further studies are required to determine how different HPV types affect the expression and function of miR-205/ CHN1 in cervical cancer.

In this study, we found that both CHN1 and miR-205 functioned as oncogenes in cervical cancer. Therefore, it seems reasonable that $m i R-205$ positively regulated CHN1. Moreover, a previous study in HeLa indicated that miR-205 mimic could increase the expression of Factin, which is involved in cell migration and cell adhesion to the extracellular matrix [42]; however, F-actin is not a direct target of miR-205. Interestingly, microinjected CHN1 colocalised in situ with F-actin in Swiss3T3 and neuroblastoma cells [28]. Therefore, regarding our current results, miR-205 may directly regulate $\mathrm{CHN} 1$ to affect F-actin expression, indirectly supporting the positive regulation of $\mathrm{CHN} 1$ by miR-205 in cervical cancer.

Interestingly, overexpression of CHN1 was not significantly associated with tumour size, the degree of tumour differentiation, or the depth of invasion in cervical cancer specimens, potentially due to the small number of clinical samples investigated. Furthermore, in differentiated squamous cell carcinoma II, the expression of CHN1was increased in cancers with lymph node metastasis compared with that in cancers without lymph node metastasis, indicating that $\mathrm{CHN} 1$ is associated with lymph node metastasis and may be a potential molecular marker of tumour metastasis. As this is the first study to demonstrate the role of CHN1 in cervical cancer, further studies are required to validate these results.

In summary, $m i R-205$ was specifically upregulated in cervical cancer, and positively regulated CHN1 to control cancer cell proliferation, invasion, and migration. These findings improved our understanding of the mechanisms of positive regulation by miRNAs and suggested that $m i R-205$ and CHN1 might play a role as a novel predictive biomarker for clinical outcomes in cervical cancer.

\section{Conclusions}

Our results have demonstrated that CHN1 and miR-205 might be used as biomarkers of human cervical cancer metastasis and potential therapeutic targets, and miR205 positively regulated the expression of $\mathrm{CHN} 1 \mathrm{in}$ human cervical cancer.

\section{Supplementary information}

Supplementary information accompanies this paper at https://doi.org/10. 1186/s12885-020-07478-w.
Additional file 1 : Supplementary Figure 1. The original drawing of the cropped blots in the Fig. 3. Red dashed line showed where the cut was made.

Additional file 2 : Supplementary Figure 2. The original drawing of the cropped blots in the Fig. 7. Red dashed line showed where the cut was made.

\section{Abbreviations}

CHN1: a1-chimaerin; HPV: Human papilloma virus; miRNAs: microRNAs; IL: Interleukin; DMEM: Dulbecco's modified eagle medium; foetal FBS: Bovine serum; DIG: Digoxigenin; UTRs: Untranslated regions; PCR: Polymerase chain reaction; WT: Wild-type; M-MLV: Moloney murine leukaemia virus; PAGE: Polyacrylamide gel electrophoresis; CCK-8: Cell counting Kit-8; PI: Propidium iodide; PS: Phosphatidylserine; NC: Negative control; AGO: Argonaute; FXR1: Fragile X mental retardation-related protein 1; AREs: AU-rich elements

\section{Acknowledgements}

Not Applicable.

\section{Authors' contributions}

$L \mathrm{LB}, X X B, H B$ conceived and designed the experiments. $L B, L Y F, C X H, Z H Q$ WSF performed the experiments. LSY provided clinical samples and performed clinical and pathological analysis. $\perp B, C X H, H J Q, X X B, H B$ analysis and interpretation of data and statistical analysis. $\perp B, X X B, H B$, WJD analyzed and discussed the data. $\sqcup B, X X B, H B$ wrote the manuscript. All authors read and approved the final manuscript.

\section{Funding}

This study was funded by Beijing Municipal Natural Science Foundation 7142126 and 7152115; the Natural Science Foundation of Guangxi, No. 2016GXNSFAA380187; Science Research Start-up Fund for Doctor of Shanxi Medical University, 03201502. All of these funds together supported the design, sampling, experimentation, data analysis, discussion, and writing of manuscript.

\section{Availability of data and materials}

All data generated or analysed during this study are included in this published article and its supplementary information files.

\section{Ethics approval and consent to participate}

Ethical approval was provided by the Ethics Committee of the National Research Institute for Family Planning and written informed consent was obtained from all participants. The number of the ethical approval is 201411. Samples and data were handled according to the declaration of Helsinki.

Consent for publication

Not applicable.

\section{Competing interests}

The authors declare that they have no competing interests.

\section{Author details}

${ }^{1}$ School of Basic Medical Sciences, Shanxi Medical University, Taiyuan 030001, People's Republic of China. ${ }^{2}$ Basic Medical College, Hebei University of Chinese Medicine, Shijiazhuang 050017, People's Republic of China. ${ }^{3}$ Reproductive Physiology Laboratory, National Research Institute for Family Planning, Beijing 100081, People's Republic of China. ${ }^{4}$ School of Pre-clinical Sciences, Guangxi Medical University, Nanning 530021, People's Republic of China.

Received: 25 June 2019 Accepted: 1 October 2020

Published online: 27 October 2020

\section{References}

1. Siegel RL, Miller KD, Jemal A. Cancer statistics, 2019. CA Cancer J Clin. 2019; 69(1):7-34.

2. Pimple S, Mishra G, Shastri S. Global strategies for cervical cancer prevention. Curr Opin Obstet Gynecol. 2016;28(1):4-10. 
3. Bartel D. MicroRNAs: genomics, biogenesis, mechanism, and function. Cell. 2004;116(2):281-97.

4. Lewis B, Burge C, Bartel D. Conserved seed pairing, often flanked by adenosines, indicates that thousands of human genes are microRNA targets. Cell. 2005;120(1):15-20.

5. Orang AV, Safaralizadeh R, Hosseinpour Feizi MA. Insights into the diverse roles of miR-205 in human cancers. Asian Pac J Cancer Prev. 2014;15(2):57783.

6. Wu X, Xi X, Yan Q, Zhang Z, Cai B, Lu W, Wan X. MicroRNA-361-5p facilitates cervical cancer progression through mediation of epithelial-tomesenchymal transition. Med Oncol. 2013;30(4):751.

7. Chu Y, Ouyang $Y$, Wang F, Zheng A, Bai L, Han L, Chen Y, Wang H. MicroRNA-590 promotes cervical cancer cell growth and invasion by targeting CHL1. J Cell Biochem. 2014;115(5):847-53.

8. Sun Y, Zhang B, Cheng J, Wu Y, Xing F, Wang Y, Wang Q, Qiu J. MicroRNA222 promotes the proliferation and migration of cervical cancer cells. Clin Invest Med. 2014;37(3):E131.

9. Hou T, Ou J, Zhao X, Huang X, Huang Y, Zhang Y. MicroRNA-196a promotes cervical cancer proliferation through the regulation of FOXO1 and p27Kip1. Br J Cancer. 2014;1 10(5):1260-8.

10. Long MJ, Wu FX, Li P, Liu M, Li X, Tang H. MicroRNA-10a targets CHL1 and promotes cell growth, migration and invasion in human cervical cancer cells. Cancer Lett. 2012;324(2):186-96.

11. Xie H, Zhao Y, Caramuta S, Larsson C, Lui WO. miR-205 expression promotes cell proliferation and migration of human cervical cancer cells. PLoS One. 2012;7(10):e46990

12. Pang H, Yue X. MiR-205 serves as a prognostic factor and suppresses proliferation and invasion by targeting insulin-like growth factor receptor 1 in human cervical cancer. Tumour Biol. 2017:39(6):1010428317701308.

13. Yuan W, Xiaoyun H, Haifeng $Q$, Jing L, Weixu H, Ruofan D, Jinjin Y, Zongji S. MicroRNA-218 enhances the radiosensitivity of human cervical cancer via promoting radiation induced apoptosis. Int J Med Sci. 2014;11(7):691-6.

14. Dong J, Sui L, Wang Q, Chen M, Sun H. MicroRNA-26a inhibits cell proliferation and invasion of cervical cancer cells by targeting protein tyrosine phosphatase type IVA 1. Mol Med Rep. 2014;10(3):1426-32.

15. Peng RQ, Wan HY, Li HF, Liu M, Li X, Tang H. MicroRNA-214 suppresses growth and invasiveness of cervical cancer cells by targeting UDP-N-acetylalpha-D-galactosamine:polypeptide N-acetylgalactosaminyltransferase 7. J Biol Chem. 2012;287(17):14301-9.

16. Yu Y, Zhang Y, Zhang S. MicroRNA-92 regulates cervical tumorigenesis and its expression is upregulated by human papillomavirus-16 E6 in cervical cancer cells. Oncol Lett. 2013;6(2):468-74.

17. Hata A, Lieberman J. Dysregulation of microRNA biogenesis and gene silencing in cancer. Sci Signal. 2015;8(368):re3.

18. Yue Z, Yun-Shan Z, Feng-Xia X. miR-205 mediates the inhibition of cervical cancer cell proliferation using olmesartan. J Renin-Angiotensin-Aldosterone Syst. 2016;17(3):1470320316663327.

19. Wu H, Zhu S, Mo YY. Suppression of cell growth and invasion by miR-205 in breast cancer. Cell Res. 2009;19(4):439-48.

20. Gandellini P, Folini M, Longoni N, Pennati M, Binda M, Colecchia M, Salvioni R, Supino R, Moretti R, Limonta P, Valdagni R, Daidone MG, Zaffaroni N. miR205 exerts tumor-suppressive functions in human prostate through downregulation of protein kinase Cepsilon. Cancer Res. 2009;69(6):2287-95.

21. Majid S, Dar AA, Saini S, Yamamura S, Hirata H, Tanaka Y, Deng G, Dahiya R. MicroRNA-205-directed transcriptional activation of tumor suppressor genes in prostate cancer. Cancer. 2010;1 16(24):5637-49.

22. Yu J, Ryan DG, Getsios S, Oliveira-Fernandes M, Fatima A, Lavker RM MicroRNA-184 antagonizes microRNA-205 to maintain SHIP2 levels in epithelia. Proc Natl Acad Sci U S A. 2008;105(49):19300-5.

23. Kim JS, Yu SK, Lee MH, Park MG, Park E, Kim SG, Lee SY, Kim CS, Kim HJ, Chun HS, Chun SW, Kim DK. MicroRNA-205 directly regulates the tumor suppressor, interleukin-24, in human KB oral cancer cells. Mol Cells. 2013; 35(1):17-24.

24. Witten D, Tibshirani R, Gu SG, Fire A, Lui WO. Ultra-high throughput sequencing-based small RNA discovery and discrete statistical biomarker analysis in a collection of cervical tumours and matched controls. BMC Biol. 2010;8:58.

25. Hou L, Zhai JJ. Aberrant expression profile of translationally controlled tumor protein and tumor-suppressive microRNAs in cervical cancer. J BUON. 2015:20(6):1504-9.
26. Ma Q, Wan $G$, Wang $S$, Yang W, Zhang J, Yao X. Serum microRNA-205 as a novel biomarker for cervical cancer patients. Cancer Cell Int. 2014;14:81.

27. Yang C, Kazanietz MG. Chimaerins: GAPs that bridge diacylglycerol signalling and the small G-protein Rac. Biochem J. 2007;403(1):1-12.

28. Kozma R, Ahmed S, Best A, Lim L. The GTPase-activating protein nchimaerin cooperates with $\mathrm{Racl}$ and $\mathrm{Cdc} 42 \mathrm{Hs}$ to induce the formation of lamellipodia and filopodia. Mol Cell Biol. 1996;16(9):5069-80.

29. Sanz-Moreno V, Gadea G, Ahn J, Paterson H, Marra P, Pinner S, Sahai E, Marshall CJ. Rac activation and inactivation control plasticity of tumor cell movement. Cell. 2008;135(3):510-23.

30. Futreal PA, Coin L, Marshall M, Down T, Hubbard T, Wooster R, Rahman N, Stratton MR. A census of human cancer genes. Nat Rev Cancer. 2004;4(3): $177-83$.

31. Kinsel LB, Szabo E, Greene GL, Konrath J, Leight GS, McCarty KS Jr. Immunocytochemical analysis of estrogen receptors as a predictor of prognosis in breast cancer patients: comparison with quantitative biochemical methods. Cancer Res. 1989;49(4):1052-6.

32. Dar AA, Majid S, de Semir D, Nosrati M, Bezrookove V, Kashani-Sabet M. miRNA-205 suppresses melanoma cell proliferation and induces senescence via regulation of E2F1 protein. J Biol Chem. 2011;286(19):16606-14.

33. Feber A, Xi L, Luketich JD, Pennathur A, Landreneau RJ, Wu M, Swanson SJ, Godfrey TE, Litle VR. MicroRNA expression profiles of esophageal cancer. J Thorac Cardiovasc Surg. 2008;135(2):255-60.

34. Matsushima K, Isomoto $H$, Yamaguchi N, Inoue N, Machida H, Nakayama T, Hayashi T, Kunizaki M, Hidaka S, Nagayasu T, Nakashima M, Ujifuku K, Mitsutake N, Ohtsuru A, Yamashita S, Korpal M, Kang Y, Gregory PA, Goodall GJ, Kohno S, Nakao K. MiRNA-205 modulates cellular invasion and migration via regulating zinc finger E-box binding homeobox 2 expression in esophageal squamous cell carcinoma cells. J Transl Med. 2011;9:30.

35. Chung TK, Cheung TH, Huen NY, Wong KW, Lo KW, Yim SF, Siu NS, Wong YM, Tsang PT, Pang MW, Yu MY, To KF, Mok SC, Wang WW, Li C, Cheung AY, Doran G, Birrer MJ, Smith DI, Wong YF. Dysregulated microRNAs and their predicted targets associated with endometrioid endometrial adenocarcinoma in Hong Kong women. Int J Cancer. 2009;124(6):1358-65.

36. Tran N, McLean T, Zhang X, Zhao CJ, Thomson JM, O'Brien C, Rose B. MicroRNA expression profiles in head and neck cancer cell lines. Biochem Biophys Res Commun. 2007;358(1):12-7.

37. Iorio MV, Visone R, Di Leva G, Donati V, Petrocca F, Casalini P, Taccioli C, Volinia S, Liu CG, Alder H, Calin GA, Menard S, Croce CM. MicroRNA signatures in human ovarian cancer. Cancer Res. 2007;67(18):8699-707.

38. Wilting SM, Snijders PJ, Verlaat W, Jaspers $A$, van de Wiel MA, van Wieringen WN, Meijer GA, Kenter GG, Yi Y, le Sage C, Agami R, Meijer CJ, Steenbergen RD. Altered microRNA expression associated with chromosomal changes contributes to cervical carcinogenesis. Oncogene. 2013;32(1):106-16.

39. Vasudevan $S$, Tong $Y$, Steitz JA. Switching from repression to activation: microRNAs can up-regulate translation. Science. 2007;318(5858):1931-4.

40. Su N, Qiu H, Chen Y, Yang T, Yan Q, Wan X. miR-205 promotes tumor proliferation and invasion through targeting ESRRG in endometrial carcinoma. Oncol Rep. 2013;29(6):2297-302.

41. Jimenez-Wences H, Peralta-Zaragoza O, Fernandez-Tilapa G. Human papilloma virus, DNA methylation and microRNA expression in cervical cancer (review). Oncol Rep. 2014;31(6):2467-76.

42. Yu J, Peng H, Ruan Q, Fatima A, Getsios S, Lavker RM. MicroRNA-205 promotes keratinocyte migration via the lipid phosphatase SHIP2. FASEB J. 2010:24(10):3950-9.

\section{Publisher's Note}

Springer Nature remains neutral with regard to jurisdictional claims in published maps and institutional affiliations. 